\title{
The Level of Vitamin A and Selenium of Cystic Echinococcosis in Aba and Garze Tibetan Autonomous Prefecture, Sichuan, China
}

\section{Cheng Li}

Affiliated hospital of Southwest Medical University https://orcid.org/0000-0002-2398-7421

\section{Yongqi Bai}

Affiliated Hospital of Southwest Medical Unversity

\section{Mingcai Zeng}

Ruoergai County People's Hospital

\section{Yong Luo}

Ruoergai County Center for Disease Control and Prevention

\section{Chumu Luorong}

Daofu County Center for Disease Control and Prevention

\section{Chuan Jin}

Affliated Hospital of Southwest Medical University

\section{Qulian Guo}

Affiliated Hospital of Southwest Medical University

\section{Qian Wang}

Sichuan Provincial Center for Disease Control and Prevention

Wenjun Liu ( $\square$ Iwjlyfy@sina.com )

Affiliated Hospital of Southwest Medical University

\section{Research Article}

Keywords: Vitamin A, Selenium, Cystic echinococcus, Tibetan

Posted Date: July 15th, 2020

DOI: https://doi.org/10.21203/rs.3.rs-40255/v1

License: (c) (i) This work is licensed under a Creative Commons Attribution 4.0 International License. Read Full License 


\section{Abstract \\ Background}

Cystic echinococcus (CE), endemic in Asia, causes disease resulting in a high socioeconomic burden.

\section{Methods}

Eighty-nine echinococcosis patients and 274 controls from the Aba and Garze Tibetan Autonomous Prefecture of Sichuan province in China were recruited. The serum levels of Selenium (Se) and vitamin A (VA) of the cases and controls were detected and stratified by age and gender.

\section{Results}

The results showed that the male to female ratio of the patients was 1:1.97. The echinococcosis patients were mainly adults. It was confirmed that the serum levels of VA and age were correlated. Compared with the healthy controls, the serum levels of Se and VA of the cases significantly declined in both children and adults.

\section{Conclusions}

It was confirmed that the serum levels of Se and VA were interrelated with the prevalence of echinococcosis.

\section{Background}

Cystic echinococciasis (CE), a hydatid disease, is a neglected yet serious threat to public health[1]. The parasitic disease is caused by the ingestion of tapeworm eggs from the species E. granulosus s.s. (G1) and $E$. canadensis $(G 6 / 7, G 8$, and G10) [2, 3]. These species of the echinococcus are highly endemic to China and especially prevalent in the western provinces including Sichuan[4-6]. On an individual level the disease presents a poor prognosis, with high morbidity and mortality rates and causes serious socioeconomic costs [7] often to already vulnerable populations. Infection is highly variable in endemic regions and dependent upon human behavioral risk factors[8].

CE is most commonly associated with the liver[3], an important metabolic organ. The liver stores and metabolizes trace elements including Vitamin A (VA) and Selenium (Se). VA is needed for normal growth and development and maintenance of regular reproductive ability. Variations in the levels of trace elements can influence immune function as well as the infection status of parasite[9]. Researchers have begun to study the relationship between trace elements and echinococciasis. Yet the serum levels of vitamin A and selenium in Sichuan are limited. In this study, we analyzed the serum levels of Se and VA in 
echinococciasis patients and healthy controls in Aba and Garze Tibetan Autonomous Prefecture of Sichuan, China.

\section{Methods}

\section{Study location and screening of human CE cases}

In 2019, 89 CE patients were selected from Ruoergai County Center for Disease Control and Prevention of Aba Tibetan and Qiang Autonomous Prefecture and Daofu County Center for Disease Control and Prevention of Garze Tibetan Autonomous Prefecture, all the patients were confirmed through B-ultrasonic examination. The control group were the 274 healthy local residents. The case to control ratio was 1:3.08.

\section{Data Collection}

Blood samples $(1 \mathrm{~mL})$ were collected from the cases and controls with coagulant and centrifuged at $3000 \mathrm{rmp}$ for $10 \mathrm{~min}$. The serum was collected and stored at $-20^{\circ} \mathrm{C}$. Before detection, the standard curve was established. $20 \mu \mathrm{L}$ serum was mixed with $50 \mathrm{~mL}$ methyl alcohol (contain $0.5 \mu \mathrm{g} / \mathrm{mL}$ internal standard of Vitamin A acetate 3-4\% CIS). After degeneration, precipitation, and mixture with trichloromethane, retinol was extracted completely. Finally, $180 \mu \mathrm{L}$ retinol was isolated and dried by nitrogen and dissolved with $100 \mu \mathrm{L}$ methyl alcohol (contain $5 \%$ dichloromethane). The liquid was used to detect VA by HPLC-

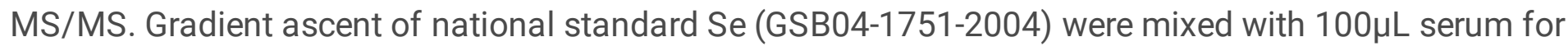
the Se test. After 15 minutes standing, the sample was diluted by Nitric acid solution and detected using ICP-MS.

\section{Data Analysis}

Location, sex, and age of the cases were analyzed with descriptive statistical methods. Spearman correlation analysis was performed to measure the statistical dependence between combinations of the variables using SPSS. The criterion for significance was $P<0.01$.

\section{Results}

Eighty-nine CE patients and 274 healthy controls from the Aba and Garze Tibetan Autonomous Prefecture of Sichuan (Table 1). The average age of cases was 39.3 (22.2) while the average age of the controls was 16.6 (11.5). Of the 89 echinococciasis cases, 30 were males $(33.7 \%)$ and 59 were females $(66.3 \%)$. The male to female ratio of the cases was 1:1.97. Of the 274 controls 137 were males (50.0\%) and 137 were female $(50.0 \%)$. The male to female ratio of the cases was $1: 1$. The echinococciasis patients were divided into 2 age groups children and adults. Of the cases 29 were children (32.6\%) and 60 were adults $(67.4 \%)$. The ratio of adults to children was $1: 2.1$. Of the controls 205 were children $(74.8 \%)$ and 69 were adults $(25.2 \%)$. The ratio of adults to children was 1:3.0. 
Table 1

Demographic factors for all echinococcosis patients and control

\begin{tabular}{|c|c|c|c|}
\hline \multicolumn{2}{|c|}{ Demographic factors } & Patients & Control \\
\hline \multicolumn{2}{|c|}{ Age (Mean \pm SD) } & $39.3 \pm 22.2$ & $16.6 \pm 11.5$ \\
\hline \multicolumn{2}{|l|}{ Children } & 29 & 205 \\
\hline \multicolumn{2}{|l|}{ Adults } & 60 & 69 \\
\hline \multicolumn{2}{|c|}{ Gender (M/F) } & $30 / 59$ & $137 / 137$ \\
\hline \multirow[t]{2}{*}{ Selenium } & Deficiency & 44 & 226 \\
\hline & Normal & 45 & 48 \\
\hline \multirow[t]{3}{*}{ VA } & Deficiency & 47 & 89 \\
\hline & Subclinical deficiency & 35 & 108 \\
\hline & Normal & 7 & 77 \\
\hline
\end{tabular}

In this study 44 cases $(49.4 \%)$ demonstrated Se deficiency while 45 cases $(51.6 \%)$ presented normal serum Se levels. In the controls, $226(82.5 \%)$ reported Se deficiency while 48 (17.5\%) had normal Se serum levels. In this study, 47 cases $(52.8 \%)$ had VA deficiency, 35 cases $(39.3 \%)$ subclinical deficiency, and only 7 (7.9\%) had normal serum VA levels. Among the controls, $89(32.5 \%)$ demonstrated deficiency, 108 (39.4\%) subclinical deficiency, and 77 (28.1\%) presented normal serum VA readings.

When Se deficiency level was stratified by gender and age group, females and children had a higher number of Se deficiency cases as compared to males and adults without a significant difference (Fig. 1). Similarly, when VA deficiency level was stratified by gender and age, females and children had a higher number of VA deficiency cases as compared to males and adults with a significant difference among the age stratified comparison (Fig. 2).

The correlation between the variables of VA deficiency, age and gender demonstrates a significant effect only for VA deficiency and age (Table 2). 
Table 2

Spearman correlation analysis among Selenium deficiency, VA deficiency and age/gender

\begin{tabular}{|lll|}
\hline Variable & \multicolumn{2}{l|}{ Spearman correlation } \\
\cline { 2 - 3 } & Correlation coefficient & P value \\
\hline Selenium deficiency and Gender & 0.125 & 0.242 \\
\hline Selenium deficiency and Age & -0.103 & 0.337 \\
\hline VA deficiency and Gender & -0.06 & 0.605 \\
\hline VA deficiency and Age & 0.281 & 0.008 \\
\hline Selenium deficiency and VA deficiency & 0.014 & 0.895 \\
\hline
\end{tabular}

When VA deficiency level was stratified by age among cases/controls, both children and adult cases had significantly higher VA deficiency as compared to controls (Fig. 3). When Se deficiency level was stratified by age among cases/controls, both children and adult cases had significantly higher Se deficiency as compared to controls (Fig. 4).

\section{Discussion}

There is an important relationship between trace elements and parasite infection. Many parasites can reduce the levels of trace elements of host, such as Se [10]. The body needs more trace elements while combating a parasite infection. Echinococcus cysts also absorb trace elements from the host to support their growth and development. Therefore, the serum level of Se and VA of an echinococciasis patient will be lower than in echinococcus cyst fluid[11, 12].. This interdependency may support a possible cure for parasitic disease.

In this study, the data of 89 echinococciasis patients in Aba and Garze Tibetan Autonomous Prefecture of Sichuan province were analyzed. The male to female ratio of the cases was 1:1.97 and gender is a known risk factor for infection $[3,8]$. This known risk factor is often explained by cultural economic production habits, as women are often engaged in animal raising and the upkeep of the home increasing their exposure of the echinococcus cyst via infected dogs and livestock[3, 8].

The echinococciasis patients were mainly adults (58\%) where the controls skewed towards a lower age range. Age is a known risk factor for echinococcus infection[3, 8]..Adults have more opportunity to be infected with echinococcus cyst while in productive activities. Due to the lack of early diagnosis of echinococciasis, young cases infected with echinococcus cyst are rarer. Most studies lack data on infections in children[13] while ours was able to account for their inclusion.

In this study, the serum levels of Se and VA of the echinococciasis patients were significantly downregulated compared with the healthy people, which was consistent with the result of a previous 
study13]. Animal studies also show similar results in the decline of VA in hydatid infected specimens [14]. Sufficient damage to the liver, due to the number and type of parasites, can cause acute and chronic hepatic insufficiency influencing the digestion, absorption, or metabolism of trace elements. Furthermore, progressive liver disease results in noted depletion of hepatic retinoid and VA content in humans[15].

The results suggest that Se and/or VA may be important trace elements for the treatment and prevention of echinococciasis. The change of trace elements might be due to host resistance to the ehcinococcus cyst or the growth of echinococcus cyst by absorbing trace elements. Research about the relationship between the trace elements and echinococciasis are limited especially in humans. Further studies are needed to delineate the role of trace elements in the survival, growth, and development of the echinococcus cyst. Also, research should clarify how the increase of trace elements in the host may prevent and/or treat echinococciasis. The influence of trace elements on host immune function is unknown. Furthermore, studies on the standard levels of trace elements in varying populations would assist in future evaluations.

\section{Conclusions}

Eighty-nine Echinococcosis patients and 274 healthy controls from the Aba and Garze Tibetan Autonomous Prefecture of Sichuan province in China were included in this study. The serum levels of Se and VA of the cases and controls was detected and stratified by age and gender. It was confirmed that the serum levels of VA and age were correlated and that VA was significantly downregulated in echinococcosis patients. Female infection was greater at 1:1.97 and the echinococcosis patients were mainly adults. Compared with the healthy controls, the serum levels of Se and VA of the cases significantly declined in both children and adults.

\section{Abbreviations}

CE

Cystic echinococciasis

VA

Vitamin A

Se

Selenium

\section{Declarations}

\section{Ethics approval and consent to participate}

Thisstudyprotocols was approved by the Ethics Committee of Affiliated Hospital of Southwest Medical University(KY2019012). 
Not applicable.

\section{Availability of data and materials}

The datasets used and/or analysed during the current study are available from the corresponding author on reasonable request.

\section{Competing interests}

The authors declare that they have no competing interests.

\section{Funding}

This study was financially supported by the Finance of Sichuan Province.

\section{Authors' contributions}

CLconceived and designed the study.CL,YB,MZ,YL,CMLR performed the study.

$\mathrm{CL}, \mathrm{CJ}, \mathrm{QG}, \mathrm{QW}, \mathrm{WL}$ analyzed and contributed reagents, materials, or analysis tools.CL wrote the paper. All authors reviewed the manuscript.

\section{Acknowledgements}

The authors thank Professor Tingyu Li for technical support and guidance.

\section{References}

1. McManus DP, Gray DJ, Zhang W, Yang Y. Diagnosis, treatment, and management of echinococcosis. Bmj. 2012;344:e3866.

2. Ito A, Budke CM. The echinococcoses in Asia: The present situation. Acta Trop. 2017;176:11-21.

3. Zhang T, Zhao W, Yang D, Piao D, Huang S, Mi Y, et al. Human cystic echinococcosis in Heilongjiang Province, China: a retrospective study. BMC Gastroenterol. 2015;15:29.

4. Craig PS, Li T, Qiu J, Zhen R, Wang Q, Giraudoux P, et al. Echinococcoses and Tibetan Communities. Emerg Infect Dis. 2008;14(10):1674-5.

5. Deplazes P, Rinaldi L, Alvarez Rojas CA, Torgerson PR, Harandi MF, Romig T, et al. Global Distribution of Alveolar and Cystic Echinococcosis. Adv Parasitol. 2017;95:315-493.

6. Wang Z, Wang X, Liu X. Echinococcosis in China, a review of the epidemiology of Echinococcus spp. Ecohealth. 2008;5(2):115-26.

7. Budke CM, Deplazes P, Torgerson PR. Global socioeconomic impact of cystic echinococcosis. Emerg Infect Dis. 2006;12(2):296-303.

8. Possenti A, Manzano-Roman R, Sanchez-Ovejero C, Boufana B, La Torre G, Siles-Lucas M, et al. Potential Risk Factors Associated with Human Cystic Echinococcosis: Systematic Review and Meta- 
analysis. PLoS Negl Trop Dis. 2016;10(11):e0005114.

9. Li WXK, Xu GR, et al. Current status on prevalence and control of echinococcosis in Ganzi Tibetan Autonomous Prefecture. Int J Med Parasit Dis. 2011;38:315-7.

10. Wang YZL, Liu H, et al. Effect of superposition infection of CVB4 and CVB3m on T cell subgroups of Kunming mice with deficiency of Se. Chin J Ctrl Endem Dis. 2001;16:1-3.

11. Wang YNHC, Feng J, et al. Analysis on Serum Trace Elements in Pregnant Mice with Schistosomiasisjaponicum. Stu Trace Elem Heal. 2001;18:3-4.

12. Mahdi JK, Al-Jawher MH, Mahdi NK. Zinc and copper levels in hydatid cyst fluid and patient's blood. J Pak Med Assoc. 2010;60(7):580-1.

13. Li JJ, Li W, Xu GR, Xu KJ, Ye P, Quan Y, et al. Analysis on Serum Trace Element Levels of Echinococciasis Patients in Garze Tibetan Autonomous Prefecture in Sichuan, China, 2011. Biomed Environ Sci. 2015;28(9):683-6.

14. Jalilzadeh-Amin G, Esmaeilnejad B, Farhang-Pajuh F. Study on the Relationship between Liver Parasitic Infections and Serum Vitamin A and beta-Carotene Status in Cattle. 2017(2146-3077 (Electronic)).

15. Ralli EPPE, Paley K, Bauman KP.. Vitamin A and carotene content of human liver in normals and diseased subjects. Archiv Inter Med. 1941;68:102-11.

\section{Figures}

A

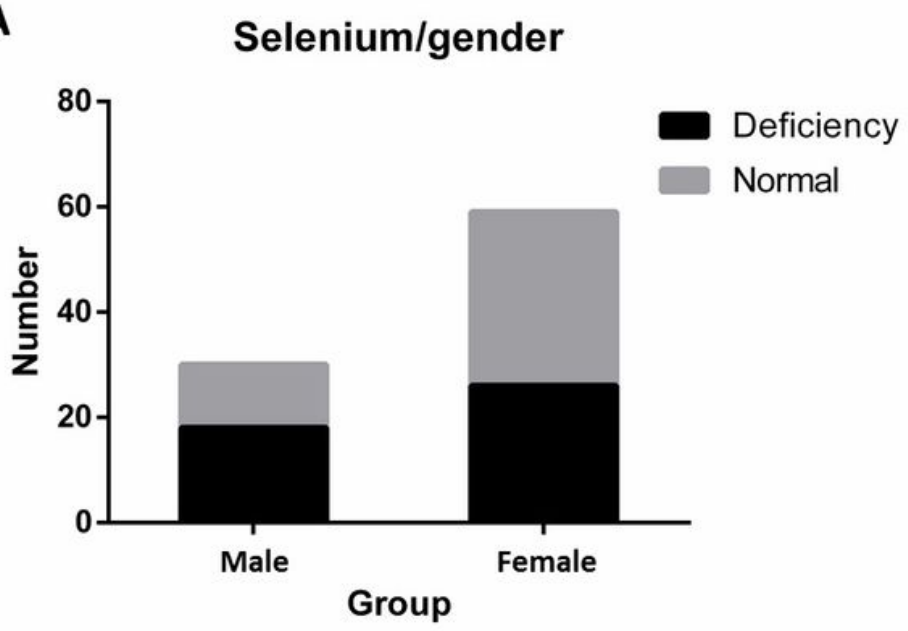

B

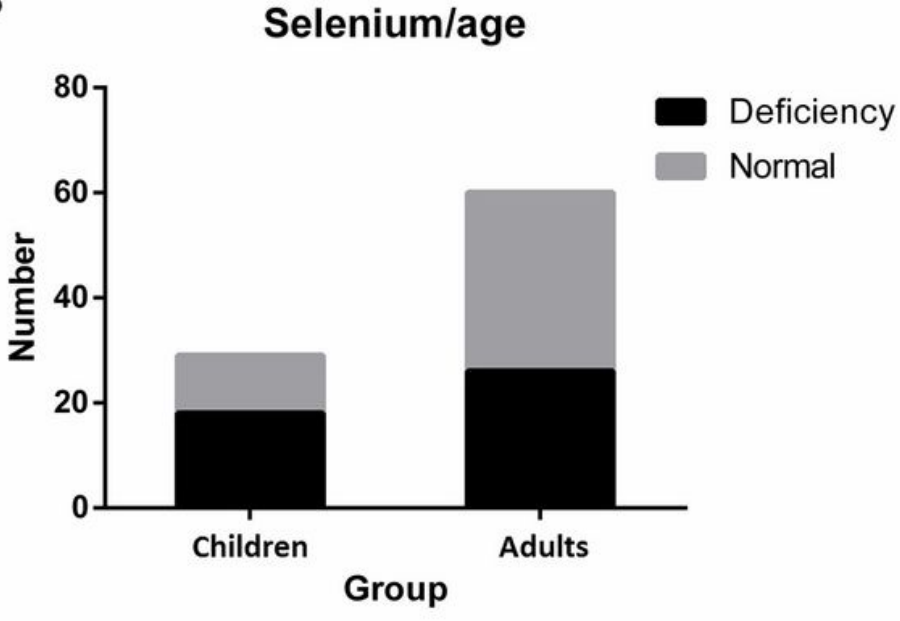

\section{Figure 1}

Selenium deficiency distribution in age and gendersubgroup of patients A: Selenium deficiency and normal selenium patients distribution in female and male group. B: Selenium deficiency and normal selenium patients distribution in child and adult group. 
A

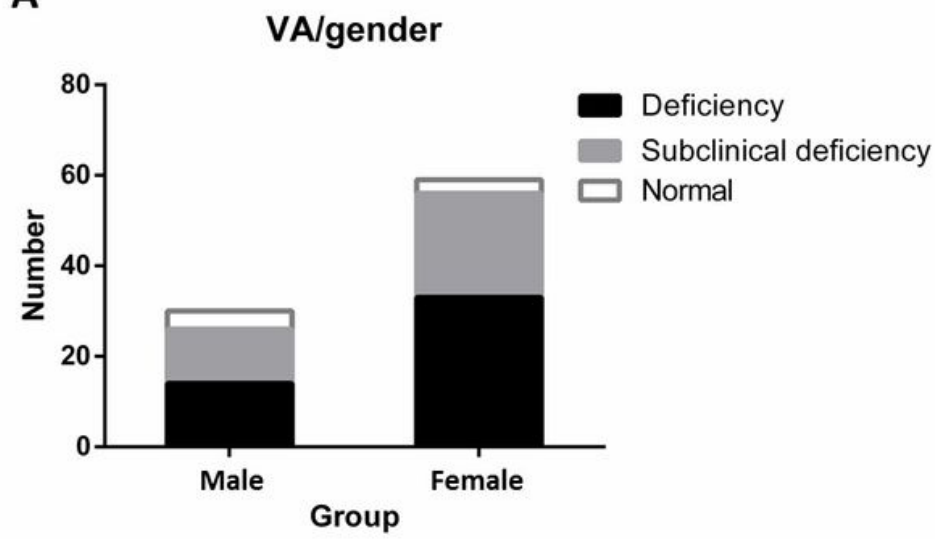

B

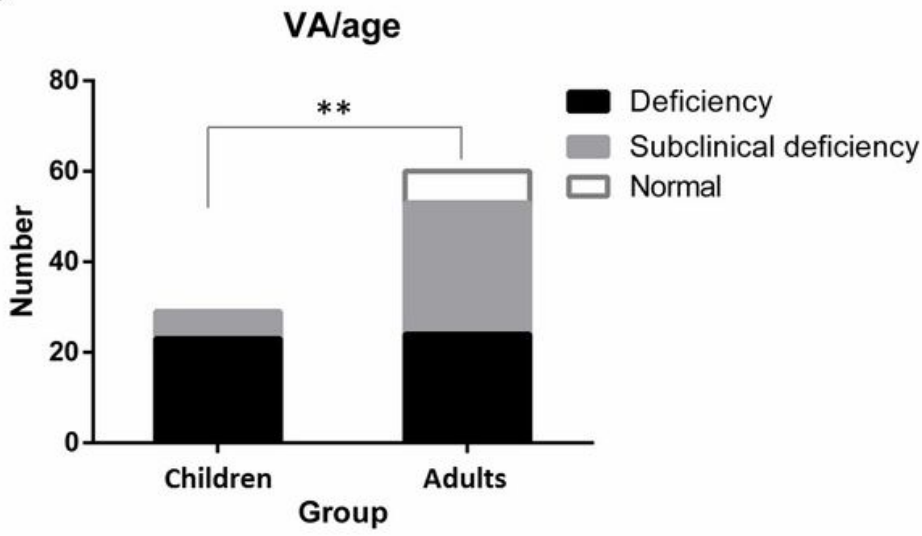

Figure 2

VA deficiency distribution in age and gender subgroup of patients A: VA deficiency and normal VApatients distribution in female and male group. B:VA deficiency and normal VApatients distribution in child and adult group. ${ }^{* *} \mathrm{P}<0.01$, chi-squaretest.

A

VA-Children

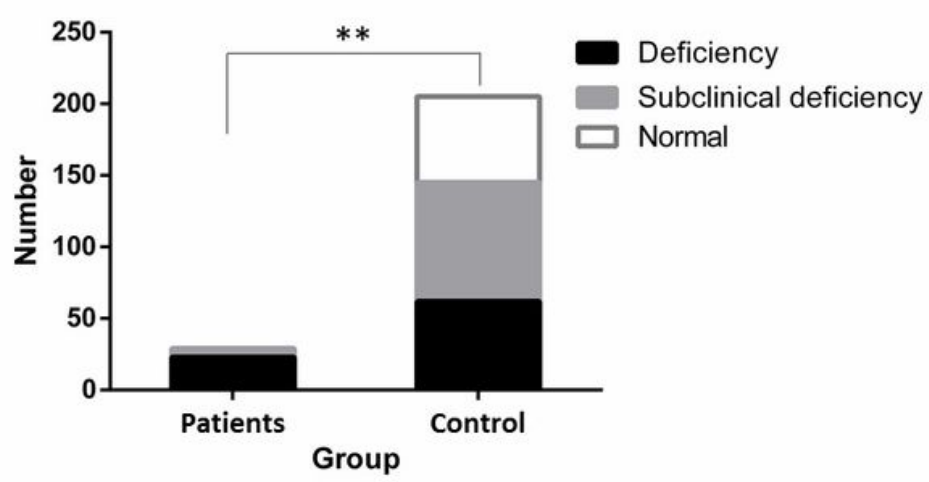

B

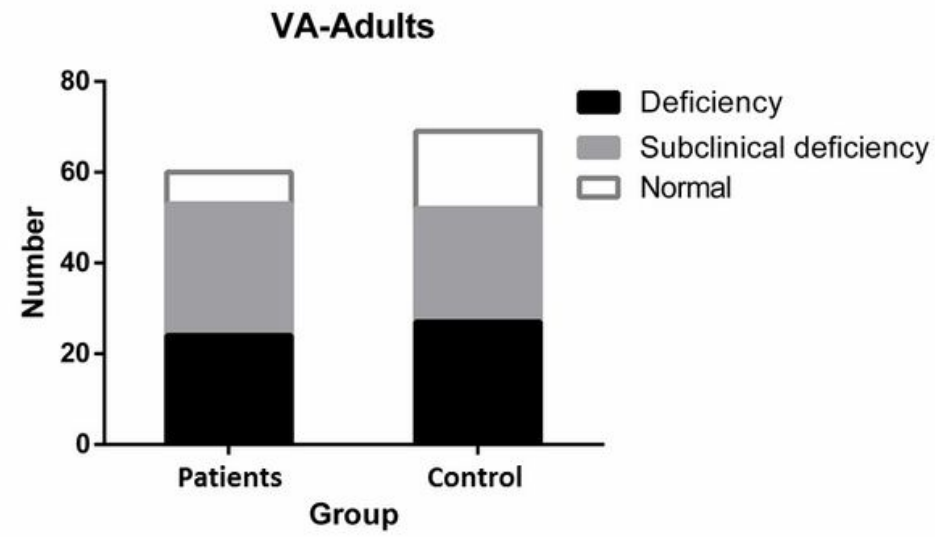

\section{Figure 3}

Comparison of VA deficiency distribution in children and adults between patients and control A: VA deficiencydistribution in children subgroup of patients and control. B:VA deficiencydistribution in adults subgroup of patients and control. ${ }^{*} \mathrm{P}<0.01$, chi-square test. 
A

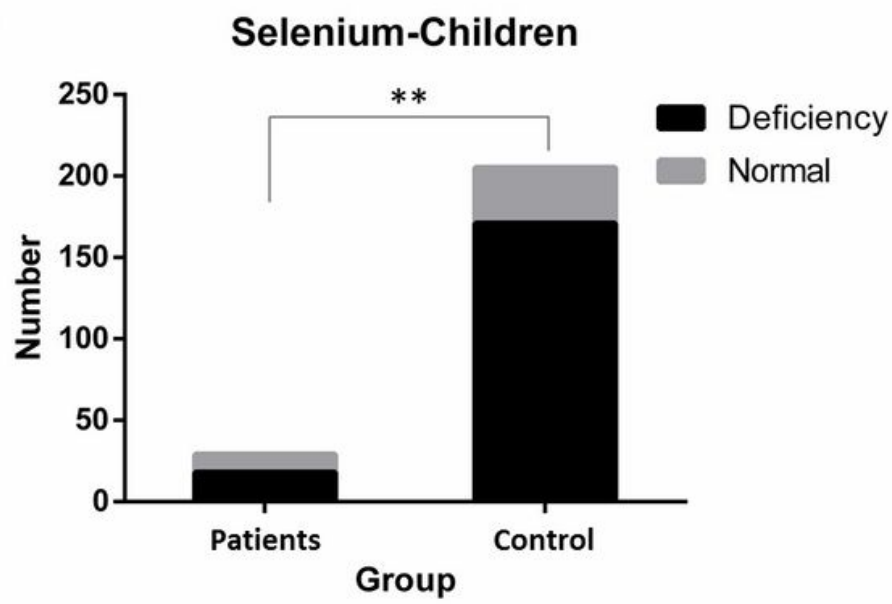

B

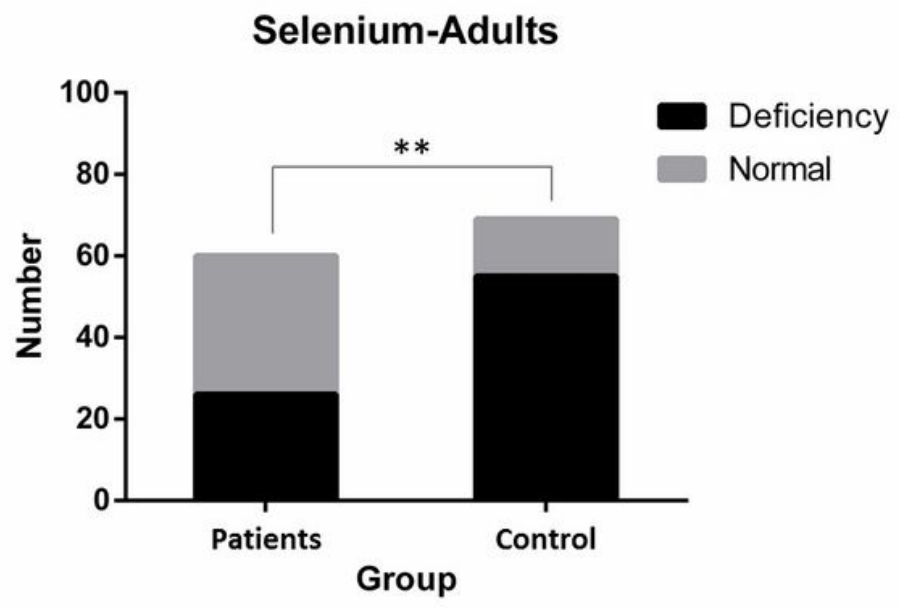

Figure 4

Comparison ofSelenium deficiency distribution in children and adults between patients and control A: Selenium deficiencydistribution in children subgroup of patients and control. B:Selenium deficiencydistribution in adult's subgroup of patients and control. ${ }^{*} \mathrm{P}<0.01$, chi-square test. 